\title{
Holistic Approach for Intervention in Geriatric Male Patient with Parkinson's Disease: A Case Study
}

\author{
Neha Tiwari* and Harshit Ambesh \\ Dr Shakuntala Misra National Rehabilitation University, India
}

Submission: December 19, 2021; Published: January 19, 2022

*Corresponding author: Neha Tiwari, Dr Shakuntala Misra National Rehabilitation University, Mohaan Road, Lucknow, India

\section{Abstract}

Parkinson's disease (PD) occurs most often in the people in their 50's and 60's. Hypokinetic dysarthria has been reported to occur in 73\% of the patients suffering from PD [1]. The disease is closely related to cognitive difficulties such as impaired attention, disorganized thinking, inefficient processing of abstract new/old information. Speech Language Pathologist's (SLP) role in the intervention of individuals with PD is not limited to working upon speech impairment but also improving various cognitive functions. This case study reflects the importance of inter-professional collaboration between neurologist, SLP along with other professionals and training of caretaker which plays a crucial role in intervention of individual with Parkinson's disease. Also, SLP's focus upon cognitive linguistic deficits, augmentative communication method and communication enhancement strategies could result in achieving communication goals.

Keywords: Parkinson's disease; Hypokinetic dysarthria; Neurologist; Caretaker training; Physiotherapist

\section{Introduction}

Parkinson's disease is a neurodegenerative disorder which is characterized clinically by resting tremor, bradykinesia, rigidity and postural instability. This condition is caused by the loss of neurons in the substantia nigra of the brain. The main communicative disorder associated with Parkinson's disease is hypokinetic dysarthria. The speech characteristics associated with hypokinetic dysarthria includes marked reduction in the amplitude of voluntary movements, slowness of movements, initiation difficulties, muscular rigidity, loss of automatic (associated) aspects of movements and tremor at rest [2]. Prevalence studies suggest that up to $30 \%$ of patients with PD develop dementia. Dementia in PD patients is often a multifactorial condition [3]. Even, in the absence of dementia, several cognitive difficulties are associated with Parkinson's disease such as impaired attention, perception/ memory, disorganized thinking, difficulty processing information, inefficient retrieval of old and stored information, inefficient problem solving. It is crucial to determine how cognitive abilities affect speech and language in geriatric population with PD. Hence, this case study aims to determine the impact of cognitive abilities over language in geriatric population with PD. The role of SLP to determine an effective treatment plan for improving cognitive skills and communication skills is highlighted.

\section{Case Study}

The case is 78 years old male referred for speech therapy from Department of Neurology, Bombay Hospital Institute of Medical Sciences on March 2021 with the diagnosis of Parkinson's disease. He was prescribed Tab Admenta $5 \mathrm{mg}$ to be taken after lunch and was also advised physiotherapy by the neurologist. A detailed speech and language evaluation was conducted. His oro-motor examination revealed that the strength and range of motion of articulators was affected. Movements of lips and tongue was found to be impaired and rigidity during movements was observed. On the Consensus Auditory-Perceptual Evaluation of Voice (CAPE V), his voice and resonance were found to be abnormal. He was unable to vary pitch and vocal intensity. Upon multiple attempts, he could phonate for the assessment of maximum phonation duration (MPD) and responded for assessment of diadochokinetic rate (DDKR). His MPD was found to be 7 seconds. The DDKR was found to be very slow. During the testing, speech intelligibility was found to be poor with less than $40 \%$ intelligibility. His speech was characterized by loss of modulation with an accelerated and or variable speaking rate causing slurring. He also displayed articulatory imprecision resulting in sound distortions. His comprehension (both 
auditory and reading) ability was found to be impaired. During evaluation of his memory skills, he did display impairment on tasks involving immediate memory. Recall of categories was also found to be affected but he could recall past memories fairly well. His reading and writing skills are also affected. He was found to be hesitant and unwilling to participate in communication esp. when a question would be asked. It was observed that instead of answering questions, he would begin to narrate incidents related to the questions. If unable to answer, he would get frustrated and agitated because of which the session would get frequently disrupted. After detailed speech and language evaluation, he was diagnosed with hypokinetic dysarthria with deficits in cognitive skills. The therapy sessions were through online mode due to the fear of spread of Covid 19. Since, the virtual mode was used, it was very important to counsel his wife and the care taker to remain actively involved during therapy. The therapy plan was directed upon postural stability, relaxation of upper body through various breathing exercises, oro- motor exercises for better oro-motor functioning. The exercises were demonstrated to the caretaker to be done every day. Cognitive Linguistic Improvement Program (CLIP)was followed which consisted of various memory, temporal orientation and categorization tasks. Activities like naming, lexical retrieval, find the missing objects, pick the odd one out, find the differences, maze games, following pattern were also used as cognitive stimulating activities. Caretaker training was also given once for appropriate home-based management. Upon discussion with the caretaker, therapy sessions were planned to be held twice a week. The duration of therapy session was 40- 50 minutes. 13 online sessions were taken. The caretaker was also counselled regarding use of pictures and test cards as an augmentative communication method.

\section{Results}

There has been regular communication between neurologist, Physiotherapist and SLP regarding goals, activities and improvement. The client has been showing improvements in various aspects of cognition that were affecting language. The use of CLIP by SLP in managing cognitive linguistic deficits along with the pharmacological treatment is helping the client's cognitive capabilities thereby increasing the use of language and interest to communicate. The patient's frustration has reduced drastically. Care taker training is regularly done as a result of which the caretaker is now able to provide proper home-based management for the client and has a better understanding of the client's special needs related to Parkinsonism. Constant guidance and counseling are provided by the speech therapist to the client, family members and caretaker. The speech intelligibility has improved to $60 \%$ due to various strategies like stressing, slow rate of speech and breaking words into syllables while speaking.

\section{Conclusion}

It is important to have a holistic approach in which cognitive, motor (fine and gross) as well as communication difficulties should be managed by a team including neurologist, physiotherapist, SLP and caretaker in management of PD. SLPs role is highlighted in this case study. SLPs are involved in planning \& working upon communication goals, guidance of care taker and care taker training. A structured caretaker is recommended in the present case study..

\section{References}

1. Selby G (1968) Cerebral atrophy in Parkinsonism. J Neurol Sci 6(3): 517-559.

2. Darley F, Aronson A, Brown (1975) Motor Speech Disorders. Philadelphia, PA/USA: Saunders.

3. Anderson KE (2004) Dementia in Parkinson's Disease. Curr Treat Options Neurol 6(3): 201-207.

\section{Your next submission with Juniper Publishers} will reach you the below assets

- Quality Editorial service

- Swift Peer Review

- Reprints availability

- E-prints Service

- Manuscript Podcast for convenient understanding

- Global attainment for your research

- Manuscript accessibility in different formats ( Pdf, E-pub, Full Text, Audio)

- Unceasing customer service

\section{Track the below URL for one-step submission}

https://juniperpublishers.com/online-submission.php 